\title{
Influence of quench rates on the properties of rapidly solidified FeNbCuSiB alloy
}

\author{
A K PANDA, I CHATTORAJ, S BASU* and A MITRA \\ National Metallurgical Laboratory, Jamshedpur 831 007, India \\ *Materials Science Centre, Indian Institute of Technology, Kharagpur 721 302, India
}

\begin{abstract}
FeNbCuSiB based materials were produced in the form of ribbons by rapid solidification techniques. The crystallization, magnetic, mechanical and corrosion behaviour were studied for the prepared materials as a function of quenching rate from liquid to the solid state. Higher quench rates produced a more amorphous structure exhibiting superior soft magnetic properties with improved corrosion resistance.
\end{abstract}

Keywords. Amorphous and nanocrystalline; magnetic properties; corrosion; crystallization.

\section{Introduction}

FeNbCuSiB based amorphous alloys exhibit excellent soft magnetic properties in their nanocrystalline state obtained by optimum heat treatment schedule (Yoshizawa et al 1988). These materials are initially prepared in the amorphous state by melt spinning technique, which involves rapid solidification of the alloy melt by impinging it on a rotating quenching wheel. As these materials are in a metastable state, their properties depend on the quenching conditions like crucible dimension, quenching rate etc. The quenching rate changes the amount of free volume frozen in an amorphous structure which lead to different extent of topological disorder and subsequently influences the physical properties of the material (Ghannami et al 1984; Hasiak et al 1984). The present study is an attempt to investigate the effect of quench rate on crystallization, magnetic, mechanical and corrosion behaviour of the asprepared materials.

\section{Experimental}

The crystallization behaviour has been studied using differential scanning calorimeter (DSC) and thermal electrical resistivity (TER) apparatus. The magnetic properties were evaluated in an open flux configuration. Electrochemical corrosion behaviour was evaluated using potentiodynamic polarization study. The details of the experimental arrangement has been described elsewhere (Chattoraj and Mitra 1998; Mitra et al 2001). In the present study a quartz crucible with conical nozzle and $0.5 \mathrm{~mm}$ nozzle to wheel distance was used for the preparation of melt spun ribbons. Hence, wheel velocity represents the quenching rate of the material.

\footnotetext{
*Author for correspondence
}

\section{Results and discussion}

DSC study showed that crystallization temperature changed with the wheel velocity. Figure 1a shows the representative DSC plots for two wheel surface velocities, $V_{\mathrm{S}}$. Similar change in crystallization temperature was also observed in resistivity study (figure $1 \mathrm{~b}$ ). The broad exothermic peak in DSC study indicated the transformation from amorphous to nanocrystalline phase. The rise in resistivity at the onset of crystallization temperature was due to the scattering of electrons from the nanocrystalline grain boundaries. The onset of crystallization, $T_{\mathrm{X}}$, increased with the increase in quenching wheel velocity up to $32 \mathrm{~m} / \mathrm{s}$, above which no further change in crystallization temperature was observed. The parameters obtained from the resistivity studies are shown in table 1 . The low onset temperature at low wheel velocity $(<32 \mathrm{~m} / \mathrm{s})$ was due to the low cooling rate that generated nucleation centres for the crystallization in as-cast state. Different quenching wheel velocities also affected the curie temperature, $T_{\mathrm{C}}$, as seen from the thermal variation of a.c. susceptibility plots (figure 2).

Curie temperature, $T_{\mathrm{C}}$, of the ribbons have been found to decrease from $552 \mathrm{~K}$ to $528 \mathrm{~K}$ with the increase in wheel velocity from $27 \mathrm{~m} / \mathrm{s}$ to $40 \mathrm{~m} / \mathrm{s}$. This indicated that the materials with high quenching rate were having less extent of long range ordering. Similar effect was also observed by others (Mizoguchi et al 1980; Greer 1992). Room temperature resistivity, $\rho_{300}$ has been found to increase with increasing quenching wheel velocity. An effect analogous to annealing at lower quenching wheel velocity probably led to some incipient crystallization resulting in their lower room temperature resistivity values. Temperature coefficients of resistivity (TCR), $\alpha$, below crystallization temperature $\left(T_{\mathrm{X}}\right)$ were found to increase with quenching wheel velocities. The faster transformation kinetics of $\mathrm{Cu}$ clustering at higher quenched samples was the cause of such increase in $\alpha$ value (Zbroszczyk et al 1994). 
The results of the magnetic measurements for samples with different quenching rates are shown in table 2 . The decrease in coercivity and increase in susceptibility i.e. enhanced soft magnetic properties with increasing wheel velocity indicated that the lesser long range ordering existed at higher quenching rate. The variation of fracture strain with the quenching rate is shown in table 2 . The materials prepared at high quenching rate had high amorphous volume fraction with lower crystallinity and lesser grain boundary as weak links which led to higher fracture strain i.e. a more ductile ribbon.

The corrosion behaviour of the prepared alloy was studied by electrochemical technique. The potentiodynamic
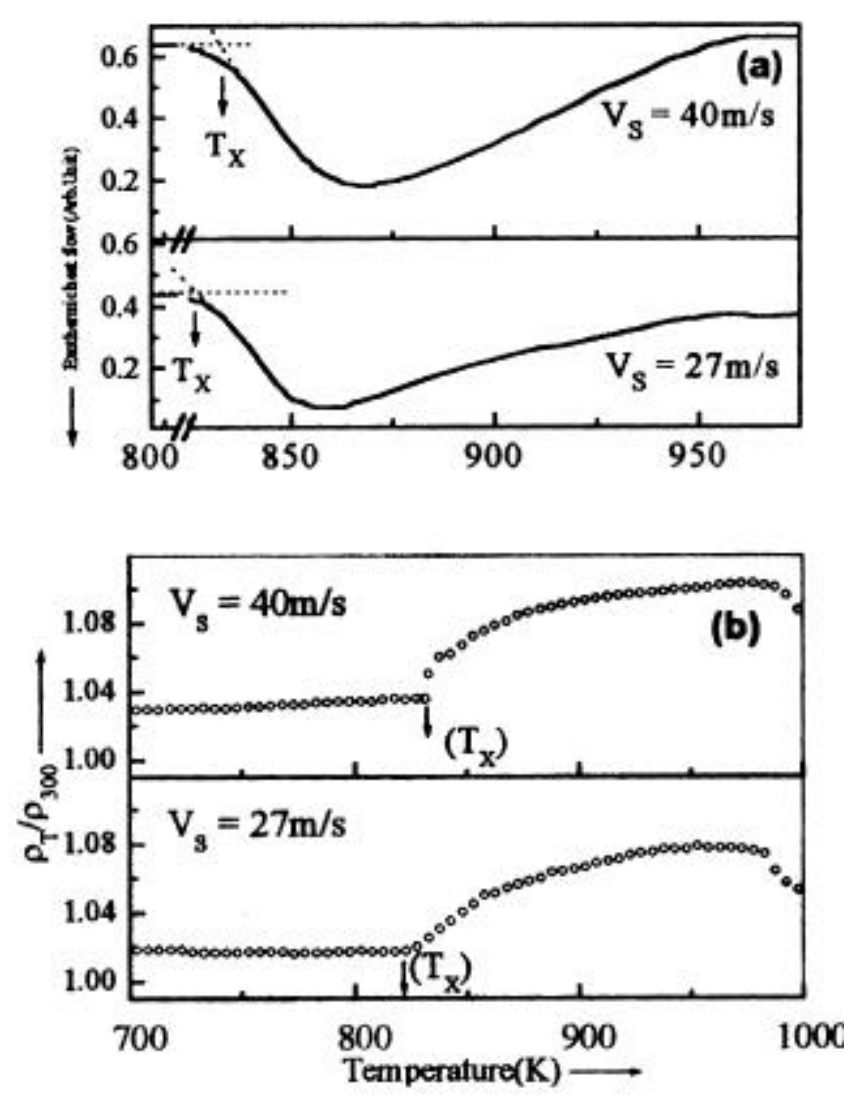

Figure 1. (a) DSC plots and (b) thermal electrical resistivity of ribbons prepared at different wheel velocities. polarization plots for different prepared ribbons are shown in figure 3. Curves (a) and (b) represent the electrochemical behaviour at two different molar strengths of $\mathrm{NaCl}$ solution. In the ribbons prepared at $27 \mathrm{~m} / \mathrm{s}$ wheel velocity, the profile of the anodic current at $0.01 \mathrm{M}$ halide strength exhibit a transient passivation around $+200 \mathrm{mV}$ (SCE) and a passivation zone extended to about $+800 \mathrm{mV}$ (SCE). However, for ribbons prepared at wheel velocities of $32 \mathrm{~m} / \mathrm{s}$ and above, the anodic activity revealed a longer passivation zone which extended close to $+1200 \mathrm{mV}$ (SCE). At a still drastic environment of $1 \mathrm{M}$ halide strength, the passivation tendency was observed only when the ribbons were prepared at wheel velocities more than $32 \mathrm{~m} / \mathrm{s}$. This portrayal of passivation profiles by a reduced

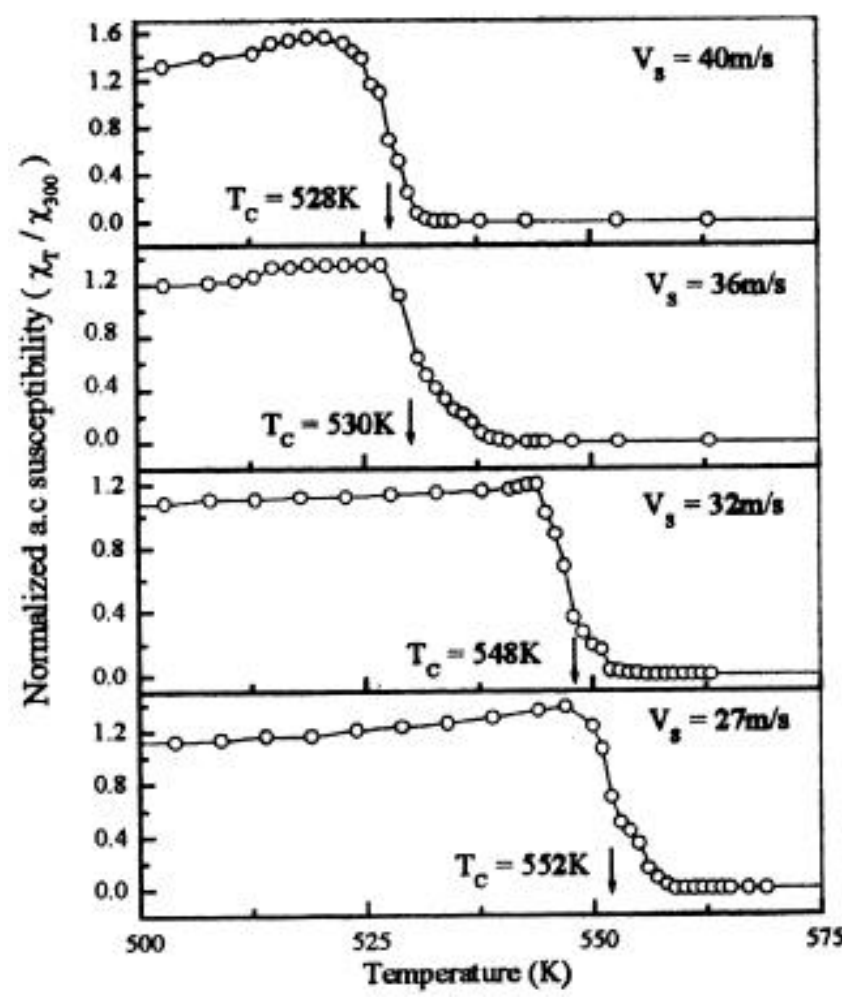

Figure 2. Thermal variation of a.c. susceptibility plots of ribbons prepared at different wheel velocities.

Table 1. Various characteristic temperatures of ribbon samples obtained from DSC and TER.

\begin{tabular}{|c|c|c|c|c|}
\hline \multirow[b]{2}{*}{$\begin{array}{l}\text { Wheel velocity } \\
(\mathrm{m} / \mathrm{s})\end{array}$} & \multirow[b]{2}{*}{$\begin{array}{l}\text { Crystallization onset } \\
\text { temperature measured } \\
\text { from DSC, } T_{\mathrm{X}}(\mathrm{K})\end{array}$} & \multicolumn{3}{|c|}{ Parameters from TER } \\
\hline & & $\begin{array}{l}\text { Room temp. } \\
\text { resistivity, } \rho_{300} \\
\left(\times 10^{-6} \Omega \mathrm{m}\right)\end{array}$ & $\begin{array}{l}\text { Crystallization } \\
\text { onset }\left(T_{\mathrm{X}}(\mathrm{K})\right)\end{array}$ & $\begin{array}{l}\text { Temp. coeff. of } \\
\text { resistivity below } T_{X} \text {, } \\
\quad \alpha\left(\times 10^{-4}\right) \mathrm{K}^{-1}\end{array}$ \\
\hline 27 & 826 & 1.85 & 822 & $0 \cdot 28$ \\
\hline 32 & 830 & 1.97 & 830 & $0 \cdot 60$ \\
\hline 36 & 832 & $2 \cdot 11$ & 832 & $1 \cdot 12$ \\
\hline 40 & 832 & $2 \cdot 25$ & 832 & 1.01 \\
\hline
\end{tabular}


Table 2. Effect of quenching wheel velocities on magnetic properties and fracture strain.

\begin{tabular}{lcccc}
\hline $\begin{array}{l}\text { Wheel } \\
\text { speed }(\mathrm{m} / \mathrm{s})\end{array}$ & $\begin{array}{c}\text { Ribbons } \\
\text { thickness } \pm 2(\mu \mathrm{m})\end{array}$ & $\begin{array}{c}\text { Coercivity }\left(H_{\mathrm{C}}\right) \\
(\mathrm{A} / \mathrm{m})\end{array}$ & $\begin{array}{c}\text { Initial suscept., } \\
\chi_{\mathrm{I}}\left(\times 10^{3}\right)\end{array}$ & $\begin{array}{c}\text { Fracture strain, } \\
\lambda_{\mathrm{f}}\left(\times 10^{-2}\right)\end{array}$ \\
\hline 27 & 36 & 3.73 & 4.82 & 0.54 \\
32 & 34 & 1.75 & 6.52 & 0.94 \\
36 & 33 & 2.07 & 7.02 & 1.11 \\
40 & 28 & 1.88 & 8.59 & 1.13 \\
\hline
\end{tabular}
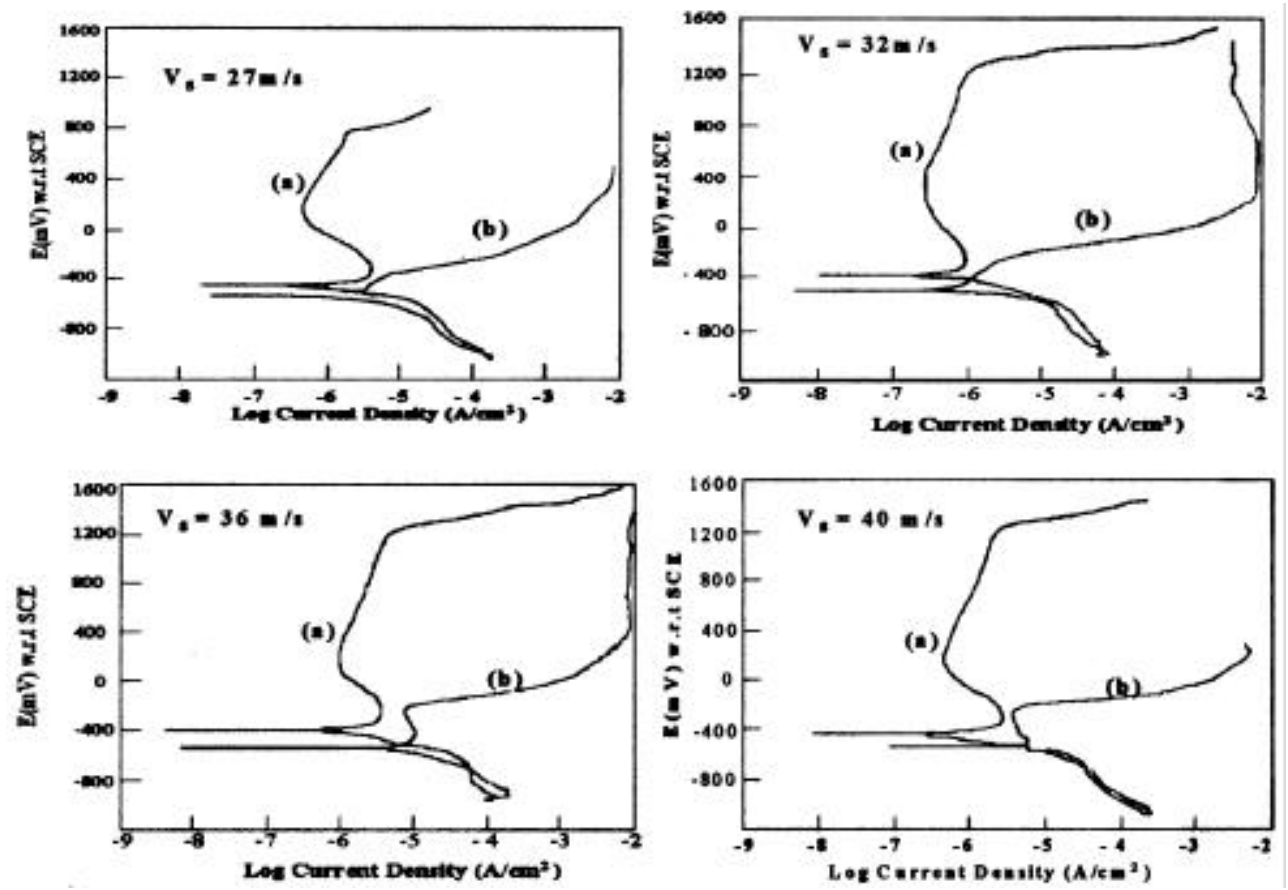

Figure 3. Potentiodynamic polarization plots of ribbons prepared at different wheel velocities carried out in $0.01 \mathrm{M}$ (a) and $1.0 \mathrm{M} \mathrm{(b)} \mathrm{NaCl}$ in buffer media.

galvanic activity in ribbons prepared at quenching wheel velocities greater than $32 \mathrm{~m} / \mathrm{s}$ showed the formation of a more homogeneous amorphous phase at higher quench rates (Naka et al 1974).

\section{Conclusion}

The quenching wheel velocities which determine the quench rate of the prepared alloy in the present study affected the crystallization, magnetic, mechanical and corrosion behaviour of the ribbons. With increase in quench rates there was an increase in crystallization onset of nanophase while the curie temperature registered a decrease. Superior soft magnetic properties, higher ductility and enhanced corrosion resistance were observed in ribbons prepared at higher quenching wheel velocities. This was due to the lack of long range ordering obtained at high quench rates.

\section{References}

Chattoraj I and Mitra A 1998 Scr. Mater. 39755

Ghannami M E I, Kulik T, Hernando A, Barquin L F, Gomez Sal J C, Gorria P and Barandiaran J M 1994 J. Magn. Magn. Mater. 133314

Greer A L 1982 J. Mater. Sci. 171117

Hasiak M, Zbroszczyk J, Olszewski J, Ciurzynska W H, Wyslocki B and Blachowicz A 1994 J. Magn. Magn. Mater. 215-216 410

Mitra A, Panda A K, Rao V, Singh S R and Ramachandrarao P 2001 J. Appl. Surf. Sci. 182321

Mizoguchi T, Hatta S, Kato H, Arai H, Maeda K and Akutsu N 1980 IEEE Trans. Magn. MAG16 147

Naka M, Hasimoto K and Masumoto T 1974 J. Jpn Inst. Metals 38835

Yoshizawa Y, Oguma S and Yamauchi K 1988 J. Appl. Phys. 646047

Zbroszczyk J, Varga L K, Olszewski J, Ciurzynska W H, Wyslocki B, Szymura S, Hasiak M and Haneczak G $1994 \mathrm{~J}$. Magn. Magn. Mater. 215-216 410 